Running head: MULTIPLE REPETITION PRIMING OF FACES

\title{
Multiple repetition priming of faces: Massed and spaced presentations
}

\author{
Karen Lander ${ }^{1}$, Vicki Bruce ${ }^{2}$, Edmund Smith ${ }^{3}$ \& Peter Hancock ${ }^{3}$ \\ 1 School of Psychological Sciences, University of Manchester \\ 2 College of Humanities and Social Science, University of Edinburgh \\ 3 Department of Psychology, University of Stirling \\ Address correspondence to: \\ Karen Lander, School of Psychological Sciences, University of Manchester, Oxford \\ Road, Manchester, M13 9PL. Telephone: +44 (0) 161275 2598, Fax: +44 (0) 161275 \\ 2588, \\ Email: karen.lander@manchester.ac.uk
}

To appear in Visual Cognition

\section{Acknowledgements}

This work was partly supported by a University of Stirling PhD studentship awarded to K. Lander, by an ESRC grant (R000 22 2989) awarded to V. Bruce and K. Lander and by an EPSRC Doctoral Training award to E. Smith.

\begin{abstract}
Previously viewing a face typically leads to a decrease in the amount of time taken to later identify it ('repetition priming'). Five repetition priming experiments are reported, which investigate whether multiple presentations of a face increase the amount of repetition priming. The results demonstrate similar amounts of priming from massed multiple presentations of the same face or a series of different images (freeze frames selected from a moving clip \& presented in sequence), compared with a single unchanging presentation (Experiments 1 \& 2). This is true even when different images are presented at prime and test (Experiment 3). However when multiple presentations were presented in a spaced fashion, with one or more intervening items between each repeat, there was significantly more priming in the multiple than single presentation condition (Experiment 4). This was true even when the face was named only once in both the multiple and single spaced conditions (Experiment 5). The results are discussed in relation to face motion.
\end{abstract}




\section{Introduction}

Previously viewing a face typically leads to a decrease in the amount of time taken to identify it on subsequent occasions (see for example Bruce et al., 1994). This effect is termed 'repetition priming' and occurs regardless of whether intervening items are viewed between study and test. Repetition priming effects have been found for word (Morton, 1979) and object recognition (Warren \& Morton, 1982), as well as face recognition.

While repetition priming effects are known to be long lasting (Flude, 1993; Maylor, 1998), there are a number of factors known to influence the amount of priming. For example, face priming is typically mediated by similarity between prime and test. Accordingly, it has been found that changes in picture / pose can significantly reduce the degree of priming (Ellis, Young, Flude \& Hay, 1987; Ellis, Ellis \& Hosie, 1993; Johnston \& Barry, 2001; Johnston, Barry \& Williams, 1996). In addition, Bruce et al. (1994) showed that repetition priming of familiarity decisions was reduced if prime and target faces differ in 'format' - when primes were computer drawn cartoons and targets were photographs, or vice versa. However, in more recent work, Lander and Bruce (2004) found that a moving face primes more effectively than a static face, even when the same static face image is shown at prime and test.

Despite the large amount of research conducted on face repetition priming, there are still a number of issues that need to be addressed. One important issue considers the impact of viewing multiple images of the face, compared to a single image. Also does viewing an image more than once increase the amount of priming? An image can be viewed multiple times in two distinct ways. First, multiple presentations can be shown consecutively ('massed' presentation). Here the participant views all images within the same recognition episode, as for example, in a moving sequence. It may be that the robust priming from moving sequences (Lander \& Bruce, 2004) is due to the fact that moving sequences contain more static-based information (more instances), which provide multiple triggers to recognition.

Second, multiple presentations can be presented in a temporally distributed fashion ('spaced' presentation), with the participant responding to each presentation of the image. Research has shown that spaced repetition is more beneficial than massed repetition for a variety of explicit memory tasks ('spacing effect', see Baddeley, 1990; Dempster, 1988 for further discussion). Furthermore, a number of studies have also compared the effect of massed and spaced repetition on implicit tests of word recognition (see Challis \& Brodbeck, 1992; Jacoby \& Dallas, 1981; Roediger \& Challis, 1992). Challis and Sidhu (1993) concluded that spaced repetition produces greater priming than either massed repetition or a single presentation, although the spacing effect tends to be relatively small and somewhat variable. Interestingly, Grant and Logan (1993) found that spaced priming accumulated as a power function of the number of presentations. Typically, massed repetition results in little, if any, increase in priming beyond that obtained from a single presentation.

While these results with word priming are interesting, there are many differences between faces and words, and thus it is not necessarily true that these effects will generalize to faces. More direct evidence demonstrating the effect of repetition on face priming comes from Lewis and Ellis (1999), who investigated the effect of spaced repetition on a face categorization task. In accordance with findings from word priming studies, results demonstrated that repeated spaced viewings of a face reduced face categorization times. Furthermore, a second experiment showed that while the first few repetitions produced relatively large reductions in reaction times, the amount by which 
reaction times fell progressively decreased as the number of repetitions increased ('negative power function'). In this experiment, participants were asked to categorize faces as belonging to 'Eastenders' or 'Coronation Street' (British TV drama programs) characters, with individual faces shown up to 65 times each across different blocks of trials. With this experimental design, as the number of repetitions is increased, so too is the amount of time each face is viewed. Thus, it may be that additional priming reflects increased viewing time, rather than repetition per se. A similar issue is also found with massed repetition experiments, which typically manipulate the number of repetitions without controlling for viewing time (for example, see Challis \& Sidhu, 1993). In view of this limitation and to explore why moving images provide such robust priming, we present five experiments designed to investigate the effect of massed and spaced repetition on face repetition priming.

Before detailing our experiments more specifically, we speculate how a theoretical model of face recognition deals with multiple repetition priming, as this provides a framework for our experimental predictions. Several connectionist accounts of face processing have been outlined in the literature, the most popular being the Interactive Activation and Competition (IAC) proposed by Burton, Bruce and Johnston (1990, later developed to incorporate learning 'IACL', Burton, 1994; and a PCA front end, Burton, Bruce \& Hancock, 1999).

\section{IACL Model}

Burton et al. (1990) set out a model of face recognition which is capable in principle of explaining both semantic and repetition priming. It builds on previous functional models of face processing (Bruce \& Young, 1986; Hay \& Young, 1982), using an interactive activation and competition (IAC) network (McClelland, 1981) to provide the opportunity for simulation. This original model implements only short-term effects occurring immediately after stimulus presentation; the learning mechanism of IACL (Burton, 1994) provides a way to model longer term behaviours, such as those we are concerned with here.

The core of the model consists of four pools of units: face recognition units (FRUs), name recognition units (NRUs), person identity nodes (PINs) and semantic information units (SIUs). Units within each pool inhibit one another, but are connected to units in other pools by excitatory links. Pools of feature units are typically used to represent visual input to the FRUs; when a face is viewed, a number of feature units are stimulated. If the feature set matches that of a known face sufficiently well, the relevant FRU will become active. Activation flows on to the matching PIN, and from there to semantic information known about the person and the name recognition units.

Repetition priming can be modelled by changing the strength of the excitatory links between (a) the feature units and the FRUs, and (b) the FRUs and PINs for seen faces. When a particular face is recognised, the strength of these connections is increased, thereby allowing quicker activation of PINs and faster 'recognition'. IACL (Burton, 1994) models just the feature unit - FRU part of this, altering connection strengths with a Hebbian learning rule once unit activations have stabilised.

In IAC, if an input is maintained, activations are likely to remain stable, if it is removed, activation should gradually return to the rest state. Depending on the exact formulation of the learning rule used, one might predict no difference in priming between multiple massed presentations of the face (same or different images) and a single unchanging image presented for the same amount of time. This will depend on the way in which learning occurs, and whether the gap between presentations is sufficient for the model to treat each one as a new input. With spaced repetitions, activations will change 
to a greater extent, and we might predict that learning should occur for each presentation of the face. On this basis, we might expect that for some formulations, significantly greater priming will occur in the spaced multiple compared to the massed multiple and once conditions. Predictions about the behaviour of IACL here depend on the learning rule used, which is not formally specified in the original paper, as noted in Stevenage and Lewis (2002).

\section{The current studies}

To recap, we present five experiments designed to investigate the effect of massed and spaced repetition on face repetition priming. We also aim to explore the theoretical underpinnings of the robust priming found with moving images (Lander \& Bruce, 2004). Specifically, in Experiment 1 we compare the amount of priming from massed multiple presentations of a face (frame A) compared with a single unchanging presentation shown for the same amount of time. Thus we compare priming from A-blank-A-blank-A-blankA (multiple condition), with an unchanging A (once condition). If the reason that moving images prime so effectively is due to multiple triggers to recognition, then we predict significantly more priming in the multiple compared with the once conditions. Theoretical accounts of IACL suggest little difference in the amount of priming from the multiple and once conditions. In Experiment 2 we compare the amount of priming from massed presentations of the same image (A-blank-A-blank-A-blank-A; multiple same condition), a series of different images (freeze frames selected from a moving clip \& presented in sequence; A-blank-B-blank-C-blank-D; multiple sequence condition) and a single unchanging image (AAAA; once condition). In the test phase we present image A. Here we explore whether providing multiple but different triggers to recognition facilitates greater priming, than repetition of the same image, or a single unchanging presentation. We explore priming from a series of different images (freeze frames selected from a moving clip \& presented in sequence), as a moving sequence necessarily displays a series of slightly changing images, rather than the same image presented repeatedly. In Experiment 3 we repeat Experiment 2, except that different images are used at prime and test. Thus, we compare the amount of priming from massed presentations of the same image (A-blank-A-blank-A-blank-A; multiple same condition), a series of different images (A-blank-B-blank-C-blank-D; multiple sequence condition) and a single unchanging image (AAAA; once condition) onto a different test image (X).

In Experiment 4 we explore the effect of spaced presentation, using the same items as Experiment 1. In this experiment, presentations of frame A are interleaved with other faces, so that the same face is never presented twice in a row. Priming from four spaced presentations of frame A (multiple condition) is compared with priming from a single unchanging presentation (AAAA), presented for the same amount of time. We predict that spaced presentation of multiple images may lead to significantly more priming than in the once condition, even when the amount of viewing time is equated across conditions. Indeed, more priming from multiple spaced presentations is predicted by IACL, compared with a single unchanging presentation. Alternatively, if the previously found beneficial effects of spaced presentation are due to increased viewing time, rather than repetition per se (see Lewis \& Ellis, 1999) then there may be no or little difference in the amount of priming across the multiple and once conditions. Finally, in Experiment 5 we again explore spaced presentations except we ensure that the face is only named once, in both the multiple and once conditions. 


\section{Experiment 1}

\section{Method}

\section{Participants}

Eighteen undergraduate students (8 male; 10 female) aged between 18 and 31 years old (mean 20 years) at the University of Stirling took part in the experiment. None had taken part in any other repetition priming experiments.

\section{Stimuli}

The stimuli consisted of 24 monochrome digitised images of famous male and female personalities. All belonged to British and American television and film stars or politicians, and all were freeze frames selected from short moving clips. The faces used were drawn from an existing database of face images, often used in priming experiments of this sort (Lander \& Bruce, 2004). Thirty-two unfamiliar faces were selected from British and American TV shows, and were created in the same manner as the famous face images. A single freeze frame was selected from a moving sequence, which was originally digitised from television. Facial images comprised of heads depicted against a medium grey background. No background or clothing cues were included in any of the images although hair was shown (image 'cut' out from background) and all were sized to comfortably fit within a circular $(7.5 \mathrm{~cm}$ diameter) background. Thus at a viewing distance of $50 \mathrm{~cm}$ all images subtended a visual angle of around $8^{\circ}$. Stimuli in both the prime and test phases were presented on computer using Superlab software.

\section{Design}

The experiment had 1 within-participants factor of Prime condition (images presented once, multiple and unprimed). The dependent variable was each participant's reaction times for correct categorization of familiarity, in the test phase.

\section{Procedure}

The experiment consisted of a priming phase and a test phase. The two experimental phases were presented to the participants as separate experiments, with an unrelated experiment carried out between the two phases. The minimum and maximum times between the appearance of a prime stimulus and its reoccurrence in the test phase were between 14 and 18 minutes. This procedure is similar to that employed in a large number of studies of face repetition priming (see Brunas et al., 1990; Ellis et al., 1987).

In the prime phase participants were shown a series of famous faces and were tested individually. They were asked to name or provide some semantic information about the person displayed. Names of roles played were deemed correct, as were unambiguous descriptions of the person (for example 'Rodney Trotter' for Nicholas Lyndhurst or 'Prime Minister' for Gordon Brown). General information such as 'actor' or 'comedian' in the absence of any further information was deemed not sufficient for a correct response. Each face was followed by a 5 second inter-stimulus interval (black screen shown) in which the participant was asked to respond verbally with their answers. No feedback was given to the participant.

The 24 famous faces selected were split into three groups of eight faces. Participants were presented with two of the three groups ( $8 * 2=16$ famous faces) in the prime phase of the experiment, one group consisted of the once condition and one of the multiple condition. Participants were presented with 16 different famous faces in the prime phase, 8 shown as a single unchanging image (for $4320 \mathrm{msec}$ - once condition) and 
8 repeated four times as part of the same recognition 'epoch' (each image shown for $1080 \mathrm{msec}$, with a 50msec black screen visually separating the repeats - multiple condition). The remaining group formed the unprimed condition (faces only shown in test phase). The experiment was a repeated measures design, and the three groups of faces were counterbalanced across conditions so that each face appeared in each experimental condition, to different participants. The order of presentation in the prime phase was also randomised for each participant.

In the test phase of the experiment participants viewed 64 face images of different people, arranged in a random order (but fixed for all participants). They were asked to make a speeded familiarity judgement by manually pressing one of two keys on the computer keyboard. It is important to note that participants were specifically asked 'to judge whether each face shown was familiar or unfamiliar': they were not required to judge whether or not the face had been viewed in the earlier prime phase. Thus, the experiment involved a familiarity judgement and was not a recognition memory experiment of the kind often described in the memory literature.

Of the 64 faces viewed in the test phase, 32 belonged to famous people, 16 of which had previously been viewed by the participant in the prime phase (8 once condition and 8 multiple condition) and 8 made up the unprimed condition. In the primed conditions, the same image was shown in the test phase as the prime phase (frame A). The remaining 8 famous faces made up a 'filler' group, which had not been viewed in the prime phase and were discounted from any further analysis. These filler famous faces were included to reduce the percentage of primed trials and so to minimise possible episodic memory effects. Filler faces were never primed for anyone, whereas the 'unprimed' faces were primed for some participants. The remaining 32 faces shown in the test phase were of unfamiliar people.

Ten additional faces (five familiar and five unfamiliar) were presented at the beginning of the test phase during a practice sequence, to ensure participants knew the task requirements. The results from these practice trials were not analysed further.

\section{Results}

Recognition performance in the prime phase of the experiment was high (once condition, 90\%; multiple condition, 90\%) indicating that the famous faces used in the experiment were highly familiar to participants taking part in the experiment. The main issue of interest however concerned the participant mean correct response times at test. Here, we excluded response times under $250 \mathrm{~ms}$ or over $2500 \mathrm{~ms}$ duration. If a face was not correctly identified in the prime phase, then the response to that face, for that particular participant was disregarded. All participants correctly categorised at least 16 of the 24 faces displayed in the prime phase. Reaction times to familiar faces judged to be unfamiliar in the test phase (errors) were also eliminated from the analysis. Participants made few errors in the familiarity decision task and error rates did not differ significantly across primed conditions. Means and error rates across participants for each priming condition are presented in Table 1.

A 1 way within-participants ANOVA was carried out on the mean reaction times to familiar faces, which revealed a significant effect of Prime condition by participants $(F(2,34)=14.97, p<.001)$ and by items $(F(2,46)=12.58, p<.001)$. A Newman-Keuls a posteriori test of pairwise comparisons showed a significant difference between the unprimed condition and both the 'primed' conditions. The difference between the once and multiple conditions was not significant (critical minimum difference $=38 \mathrm{msec}$, actual difference $=1 \mathrm{msec}$ ). 
Table 1: Table showing mean correct familiarity decisions to famous faces in Experiments 1 to 5 . The error rates (\%) in each condition are also shown.

\begin{tabular}{|c|c|c|c|c|}
\hline & \multicolumn{4}{|c|}{ Prime condition } \\
\hline & Once & $\begin{array}{l}\text { Multiple } \\
\text { same }\end{array}$ & $\begin{array}{l}\text { Multiple } \\
\text { sequence }\end{array}$ & Unprimed \\
\hline \multicolumn{5}{|c|}{ Experiment 1 (massed presentation) } \\
\hline RT (msec) & 729 & 730 & - & 838 \\
\hline SD & 103 & 87 & - & 108 \\
\hline$\%$ errors & 2 & 0 & - & 4 \\
\hline \multicolumn{5}{|c|}{$\begin{array}{l}\text { Experiment } 2 \text { (massed presentation, } \\
\text { sequence \& same) }\end{array}$} \\
\hline RT (msec) & 742 & 737 & 734 & 833 \\
\hline $\mathrm{SD}$ & 94 & 98 & 103 & 130 \\
\hline$\%$ errors & 1 & 1 & 0.5 & 5 \\
\hline \multicolumn{5}{|c|}{$\begin{array}{l}\text { Experiment } 3 \text { (massed presentation, } \\
\text { sequence \& same. Different test } \\
\text { image) }\end{array}$} \\
\hline RT (msec) & 771 & 760 & 769 & 845 \\
\hline SD & 81 & 82 & 78 & 127 \\
\hline$\%$ errors & 2 & 1 & 1 & 4 \\
\hline \multicolumn{5}{|c|}{ Experiment 4 (spaced presentation) } \\
\hline RT (msec) & 779 & 715 & - & 889 \\
\hline $\mathrm{SD}$ & 124 & 103 & - & 171 \\
\hline$\%$ errors & 0 & 0 & - & 6 \\
\hline \multicolumn{5}{|c|}{ Experiment 5 (spaced, one response) } \\
\hline RT (msec) & 767 & 708 & - & 905 \\
\hline $\mathrm{SD}$ & 149 & 138 & - & 171 \\
\hline \% errors & 2 & 0.5 & - & 6 \\
\hline
\end{tabular}

\section{Discussion}

As expected familiarity judgements were significantly enhanced by prior exposure to the same face. This finding is in line with a large number of previous studies which have demonstrated repetition priming for familiar faces (for example, Bruce \& Valentine,1985; Brunas et al.,1990; Ellis et al., 1987). However there was no significant difference in the amount of priming between a single viewing of the face in the prime phase (once condition) compared to multiple viewings of that image.

The fact that we found no significant difference between the once and multiple conditions is consistent with our predictions from the IACL model (Burton 1994). According to this account, when a face is recognised, the PIN reaches its threshold value and the FRU-PIN link is strengthened as a result. Activation in the PIN is assumed to remain as long as no other face is presented (or as long as there is no time for activation to decay in the unfilled interval). Accordingly, multiple presentations of the same face 
within the same recognition epoch should not produce more repetition priming.

In Experiment 2 we explore the possibility that the robust priming from moving images can be attributed to the viewing of a structured series of different images, rather that viewing massed presentations of the same image. In Experiment 2 we compare the amount of priming from massed presentations of the same image (A-blank-A-blank-Ablank-A; multiple same condition), a series of different images (A-blank-B-blank-Cblank-D; multiple sequence condition) and a single unchanging image (AAAA; once condition). In the test phase we present Image A.

\section{Experiment 2}

\section{Method}

The Design and Procedure for this experiment were the same as those detailed in Experiment 1 except for the following details.

\section{Participants}

Eighteen undergraduate students (7 male; 11 female) aged between 18 and 26 years old (mean 20 years) at the University of Stirling took part in the experiment. None had taken part in any other repetition priming experiments.

\section{Stimuli}

The stimuli were the same 24 monochrome computer images of famous male and female personalities used in Experiment 1 plus an additional 8 faces. Most belonged to British and American television and film stars, and all were freeze frames selected from short moving clips. In the once condition, the first frame of the moving clip (frame A) was shown as an unchanging image for a total of 4320msec. In the multiple same condition, frame A was shown four times, each for $1080 \mathrm{msec}$, with a 50msec black screen visually separating the repeats. In the multiple sequence condition, different images were selected from the moving sequence. The first image was the first frame (frame A). The next static images (frames B, C, \& D) were selected at one second intervals from the moving sequence. Each frame was presented for $1080 \mathrm{msec}$, with a $50 \mathrm{msec}$ black screen visually separating the repeats. Hence the multiple sequence condition appeared to the participant as a structured series of images with little feeling of animation between views.

\section{Design}

The experiment had 1 within-participants factor of Priming (images presented in the Prime phase once, multiple same, multiple sequence or not at all (unprimed)).

\section{Procedure}

In the prime phase of the experiment participants were presented with 24 famous face images, 8 shown once and 16 shown four times in succession (8 multiple same $\& 8$ multiple sequence). Participants were asked to name, or provide some unambiguous semantic information, about each person displayed. Of the 80 faces viewed in the test phase, 40 belonged to famous people, 24 of which had previously been viewed by the participant in the prime phase (8 once condition, 8 multiple same $\& 8$ multiple sequence) and 8 made up the unprimed condition (only shown in test phase). The same image was shown in the test phase as the prime phase (frame A). The remaining 8 famous faces made up a 'filler' group, which had not been viewed in the prime phase and were 
discounted from any further analysis. The remaining 40 faces shown in the test phase were of unfamiliar people.

\section{Results}

As in Experiment 1, recognition performance in the prime phase of the experiment was high (once condition, 88\%; multiple same condition 89\%, multiple sequence condition 90\%). Means and error rates across participants to faces presented in the test phase are presented in Table 1. As with Experiment 1 only reaction times to faces judged familiar in the Prime phase were included in the means.

A 1 way within-participants ANOVA was carried out on the mean reaction times to familiar faces, which revealed a significant effect of Prime condition by participants $(F(3,51)=10.76, p<.001)$ and by items $(F(3,93)=9.05, p<.001)$. A Newman-Keuls a posteriori test of pairwise comparisons revealed that there was a significant difference between the unprimed and all primed conditions. There were no significant differences in the amounts of priming from the primed conditions (critical minimum difference $=$ 41msec).

\section{Discussion}

The results of Experiment 2 showed that there is no significant difference between the amount of priming from a series of different images (multiple sequence condition) compared with the same image shown repeatedly (multiple same condition) or an unchanging image (once condition). Before discussing the consequences of this finding, it is useful to consider the potential implications of using the same image at test as at prime (Image A). In Experiment 2 it is possible that the use of the same picture at prime and test may work against the positive influence of having different images at prime (multiple sequence condition). Here, a transfer-appropriate processing (Roediger, Weldon \& Challis, 1989) situation may be at play, such that the same (repeated) picture at prime and test gives an equivalent amount of priming as the different pictures at prime, because the benefit of the different pictures at prime is countered by the cost of having only one picture at test - the same picture that the single image group had. Given this possibility, we replicated Experiment 2, using different images at prime and test.

\section{Experiment 3}

\section{Method}

The Design and Procedure for this experiment were the same as those detailed in Experiment 2 except for the following details.

\section{Participants}

Eighteen undergraduate students (10 male; 10 female) aged between 18 and 28 years old (mean 20 years) at the University of Manchester took part in the experiment. None had taken part in any other repetition priming experiments.

\section{Stimuli}

The stimuli were the same computer images of famous male and female personalities used in Experiment 2. In the test phase, we used a perceptually different image of each famous face, collected from later on in the moving sequence (Image X; 
freeze frame collected from fifth second of clip).

\section{Design}

The experiment had 1 within-participants factor of Priming (images presented in the Prime phase once, multiple same, multiple sequence or not at all (unprimed)). The test image was different to any of those shown in the prime phase.

\section{Results}

As in Experiment 2, recognition performance in the prime phase of the experiment was high (once condition, 89\%; multiple same condition 91\%, multiple sequence condition 89\%). Means and error rates across participants to faces presented in the test phase are presented in Table 1 . As with previous experiments only reaction times to faces judged familiar in the Prime phase were included in the means.

A 1 way within-participants ANOVA was carried out on the mean reaction times to familiar faces, which revealed a significant effect of Prime condition by participants $(F(3,51)=5.20, p<.005)$ and by items $(F(3,93)=4.71, p<.005)$. A Newman-Keuls a posteriori test of pairwise comparisons revealed that there was a significant difference between the unprimed and all primed conditions. There were no significant differences in the amounts of priming from the primed conditions (critical minimum difference $=$ 49msec).

\section{Discussion}

The results of Experiment 3 replicated those in Experiment 2, and showed that there is no significant difference between the amount of priming from a series of different images (multiple sequence condition) compared with the same image shown repeatedly (multiple same condition) or an unchanging image (once condition), even when a different image is shown at test. Thus, we can discount the possibility that the use of the same picture at prime and test may work against the positive influence of having different images at prime.

Importantly, our findings from Experiments 2 and 3 suggest that the robust priming effect found with moving sequences (Lander \& Bruce, 2004) is not due to the fact that viewing a structured series of images leads to a greater likelihood of recognition. Indeed, if this were the case then we would have expected to find more priming in the multiple sequence condition compared with the multiple same condition. To summarise, the results from Experiments 1, 2 and 3 indicate that significantly greater priming is not found when multiple images are presented in a massed fashion, compared with viewing a single unchanging image even when viewing time is equated across conditions.

In Experiment 4, we compare the amount of priming obtained from multiple presentations of the same face with a single presentation of that face (for the same amount of time). In contrast to Experiments 1 to 3, participants are required to respond to each separate presentation of the face. Each viewing of the same face is presented as a separate recognition 'episode' with one or more different faces (other 'primed' faces) shown between each presentation. As with previous experiments the face is viewed four times in the multiple presentation condition. According to the IACL model (Burton, 1994) there should be significantly more priming from multiple presentations of this kind, due to the feature-FRU and FRU-PIN links being repeatedly strengthened. 


\section{Experiment 4}

\section{Method}

The Design and Procedure for this experiment were the same as those detailed in Experiment 1 except for the following details.

\section{Participants}

Eighteen undergraduate students (9 male; 9 female) aged between 18 and 37 years old (mean 22 years) at the University of Stirling took part in the experiment. None had taken part in any other repetition priming experiments.

\section{Stimuli}

The stimuli were the same 24 monochrome computer images of famous male and female personalities used in Experiment 1.

\section{Design}

The experiment had 1 within-participants factor of Priming (images presented in the Prime phase once, multiple times or not at all (unprimed)). In this case participants were required to respond to each presentation of the face in the Prime phase.

\section{Procedure}

In the prime phase of the experiment participants were presented with 16 famous face images, 8 shown once for 4320ms (8 images) and 8 shown four times, each for $1080 \mathrm{~ms}$ (8 X $4=32$ images). The order of presentation was randomised for each participant, with the constraint that the same identity was not shown more than once in a row. Participants were asked to name, or provide some unambiguous semantic information, about each face viewed, even when the same face had been viewed previously. Thus, they were asked to respond verbally to all 40 face images presented in the prime phase. Each face was followed by a 5 second inter-stimulus interval (black screen shown) in which the participant was asked to respond verbally with their answers. The test phase used was exactly the same as in Experiment 1 (same image shown at prime and test).

\section{Results}

As in previous experiments, recognition performance in the prime phase of the experiment was high (once condition, 90\%; multiple condition 89\%). Means and error rates across participants to faces presented in the test phase are presented in Table 1. As previously only reaction times to faces judged familiar in the Prime phase were included in the means. In this experiment, we discounted any face (for a particular participant) which was not correctly identified on each presentation. The data from one participant was removed and replaced, as they did not recognise the majority of the faces in the prime phase.

A 1 way within-participants ANOVA was carried out on the mean reaction times to familiar faces, which revealed a significant effect of Prime condition by participants $(F(2,34)=26.83, p<.001)$ and by items $(F(2,46)=26.05, p<.001)$. A Newman-Keuls a posteriori test of pairwise comparisons revealed that there was a significant difference between the unprimed and both primed conditions. There was also a significant difference between the once and multiple conditions (minimum critical difference $=$ 
49msecs, actual difference $=64 \mathrm{msecs})$.

\section{Discussion}

As with previous experiments a clear 'repetition priming' effect was demonstrated, with faster familiarity decision latencies to faces that had been viewed before. However in contrast to Experiments 1 to 3 a significant difference between priming conditions was found, with more priming from multiple presentations of the face (amount of priming $=174 \mathrm{msec}$ ), compared to viewing the face just once (amount of priming $=110 \mathrm{msec}$ ). It seems that multiple presentations of a face do produce more priming, provided each presentation of the face is presented as a separate instance, with the presentation of other faces between each instance. This result corresponds with the results of Lewis and Ellis (1999) who investigated the build-up of repetition priming in a face categorization task. Priming was found to accumulate as a power function of the number of presentations. We add to this finding by showing that even when the amount of time is equated across presentation types, spaced multiple presentations increases the amount of priming over a single presentation event.

One obvious difference between this experiment and Experiments 1 to 3 is that Experiment 4 required participants to respond verbally to each presentation of the face. In Experiments 1 to 3, participants viewed multiple presentations of the face but were only asked to respond verbally once. Thus, it may be that the difference in amounts of priming reflects the number of overt verbal responses required. To explore this possibility Experiment 5 repeats Experiment 4 except it asks participants to respond verbally only to the first presentation of the face image. It is predicted that even when the number of overt verbal responses is equated across conditions (once in both multiple and once conditions), the amount of priming in the multiple condition will still be greater than found in the once condition.

\section{Experiment 5}

\section{Method}

The Design and Procedure for this experiment were the same as those detailed in Experiment 4 except for the following details.

\section{Participants}

Eighteen undergraduate students (10 male; 8 female) aged between 17 and 28 years old (mean 20 years) at the University of Stirling took part in the experiment. None had taken part in any other repetition priming experiments.

\section{Stimuli}

The stimuli were the same 24 monochrome computer images of famous male and female personalities used in Experiments 1 and 4.

\section{Procedure}

The procedure used in this experiment was exactly the same as in Experiment 3 except that participants were required to respond only to the first presentation of the face in the Prime phase. Faces not recognised on the first presentation were removed from further analysis. In addition, the experimenter kept note of the number of times each face was overtly named and the data for any particular face (for an individual participant) that 
was named more than once was removed from analysis. The data from 2 faces, across all participants were removed on this basis. The test phase used was exactly the same as in Experiments 1 and 4.

\section{Results}

Recognition performance in the prime phase of the experiment was high (once condition, 91\%; multiple condition 88\%). Means and error rates across participants to faces presented in the test phase are presented in Table 1. As with previous experiments only reaction times to faces judged familiar in the Prime phase were included in the means.

A 1 way within-participants ANOVA was carried out on the mean reaction times to familiar faces, which revealed a significant effect of Prime condition by participants $(F(2,34)=26.02, p<.0001)$ and by items $(F(2,46)=15.26, p<.001)$. A planned pairwise comparison revealed a significant difference between the once and multiple conditions.

\section{Discussion}

Our results in Experiment 5 replicate those found in Experiment 4. We found significantly more priming from multiple spaced presentations of the face, compared with a single image presented for the same amount of time, even when the number of times the face is overtly named is equated across conditions.

\section{General Discussion}

The five experiments reported here allow us to make the following points:

Firstly, we have established that four massed repetitions of a face does not lead to an increase in priming, on a face familiarity task, beyond that obtained from a single unchanging presentation shown for the same amount of time (Experiments 1, 2 \& 3). This result corresponds with findings detailed in the word priming literature. For example, Challis \& Sidhu (1993) found no advantage for massed presentation on an implicit perceptual task, when participants were asked to complete a word fragment completion task at test. In contrast, Challis and Sidhu (1993) did find a priming advantage for massed repetition in an implicit conceptually driven task (general knowledge quiz at test), where there was no perceptual similiarity between study and test. This distinction between perceptual and conceptual implicit tasks is important in terms of the transfer appropriate processing account of priming (see Roediger \& Challis, 1992; Roediger et al., 1989). A basic tenet of this approach is that memory tests benefit to the extent that the type of processing promoted at study overlaps with the type of processing required for performance of the test (Morris, Bransford \& Franks, 1977). Accordingly, massed repetition is thought to promote elaborative semantic processing, explaining why massed repetition enhances priming on an implicit conceptually driven task but not an implicit perceptually driven task.

The finding that four massed repetitions of the face do not lead to an increase in priming, compared with a single unchanging presentation is also interesting when considering the impact of face motion. When a face is viewed in motion, we present a series of images shown in rapid succession (25 frames per second). Although we do not aim to explicitly investigate the theoretical underpinnings of the robust priming effect found with moving images (see Lander \& Bruce, 2004), our current results do suggest it is not due to multiple but different triggers to recognition facilitating greater priming. In Lander and Bruce (2004) we suggest that the robust priming it is related to the additional 
dynamic information available from a moving clip. Indeed, Lander and Bruce (2004) found increased priming from naturally moving faces compared with those shown in slow motion. Here the number and selection of images shown to the participant are the same in each condition, but the original dynamic characteristics of the observed motion are only retained in natural motion. Individual faces may have characteristic motion signatures, which capture idiosyncratic aspects of their facial movement (see O'Toole, Roark \& Abdi, 2002). It is likely that such dynamic information is intrinsic to the face representations, and the representations themselves may themselves be dynamic in nature (Freyd, 1987; see Lander \& Bruce, 2004).

Secondly, our results found that presenting four spaced repetitions of a face does increase priming beyond that obtained from a single unchanging presentation (Experiment 4). This finding adds to the Lewis and Ellis (1998) study by demonstrating that increased priming is found when the same face image is repeated in spaced presentations, with the amount of viewing time equated across the single and multiple conditions. It seems that additional priming is indeed a function of repetition, rather than simply a consequence of increased viewing time or naming (Experiment 5). Ongoing work is exploring the impact of spaced priming using different prime images (as in Experiments 2 and 3), over the effectiveness of spaced priming using the same prime images. More priming may result if the prime phase involves different images of the familiar target than the same image of the familiar target. This prediction follows from the fact that reinforcing the same set of feature-FRU links will gradually cease to have an effect, as the links reach their maximum potential (see Stevenage \& Spreadbury, 2006 for a discussion of waning priming for highly familiar faces). However, if the prime phase presents different images of the familiar target each time, then these presentations could continue to have a priming effect because different sets of feature-FRU links would be reinforced each time.

Finally, it is important to note that the findings from all experiments are consistent with our predictions from the IACL (Burton, 1994) model of face recognition. Within this account, repetition priming has been accounted for by the strengthening of the links between activated units. Strengthening increases according to the Hebbian learning algorithm (Burton, 1994) and occurs every time a face is recognised. Hence, repeated viewing of the face does not increase priming for massed presentation (face only recognised once) but does for spaced presentation (face recognised multiple times).

\section{References}

Baddeley, A. (1990). Human memory: Theory and practice. Needham heights, MA: Allyn \& Bacon.

Bruce, V., Burton, A.M., Carson, D., Hanna, E. \& Mason, O. (1994). Repetition priming of face recognition. Attention and Performance, 15, 179-201.

Bruce, V. \& Valentine, T. (1985). Identity priming in the recognition of familiar faces. British Journal of Psychology, 76, 363-383.

Bruce, V. \& Young, A.W. (1986). Understanding Face Recognition. British Journal of Psychology, 77, 305-327.

Brunas, J., Young, A.W. \& Ellis, A.W. (1990). Repetition priming from incomplete faces: Evidence for part to whole completion. British Journal of Psychology, 81, 43-56.

Burton, A.M. (1994). Learning new face in an interactive activation and competition model. Visual Cognition, 1, 313-348.

Burton, A.M., Bruce, V. \& Hancock, P. (1999). From Pixels to People: A model of 
Familiar Face Recognition. Cognitive Science, 23, 1-31.

Burton, A.M., Bruce, V. \& Johnston, R.A. (1990). Understanding face recognition with an interactive activation model. British Journal of Psychology, 81, 361-380.

Challis, B.H. \& Brodbeck, D.R. (1992). Level of processing affects priming in word fragment completion. Journal of Experimental Psychology: Learning, Memory \& Cognition, 18, 595-607.

Challis, B.H. \& Sidhu, R. (1993). Dissociative effect of massed repetition on implicit and explicit measures of memory. Journal of Experimental Psychology: Learning, Memory \& Cognition, 19, 115-127.

Dempster, F.N. (1988). The spacing effect : A case study in the failure to apply the results of psychological research. American Psychologist, 43, 627-634.

Ellis, H.D., Ellis, D.M. \& Hosie, J.A. (1993). Priming effects in childrens face recognition. British Journal of Psychology, 84, 101-110.

Ellis, A.W., Young, A.W., Flude, B.M. \& Hay, D.C. (1987). Repetition priming of face recognition. Quarterly Journal of Experimental Psychology, 39A, 193-210.

Flude, B.M. (1993). Long-term repetition priming of familiar faces. Unpublished doctoral dissertation, University of Lancaster, UK.

Grant, S.C., \& Logan, G.D. (1993). The loss of repetition priming and automaticity as a function of degree of initial learning. Memory \& Cognition, 21, 611-618.

Hay, D.C. \& Young, A.W. (1982). The human face. In A.W. Ellis (Ed), Normality and Pathology in Cognitive Functions. London: Academic Press.

Jacoby, L.L. \& Dallas, M. (1981). On the relationship between autobiographical memory and perceptual learning. Journal of Experimental Psychology: General, 110, 306-340.

Johnston, R.A. \& Barry, C. (2001). Best face forward: Similarity effects in repetition priming of face recognition. Quarterly Journal Of Experimental Psychology, 54A, 383-396.

Johnston, R.A., Barry, C. \& Williams, C. (1996). Incomplete faces don't show the whole picture: Repetition priming from jumbled faces. Quarterly Journal of Experimental Psychology, 49A, 596-615.

Lander, K. \& Bruce, V. (2004). Repetition priming from moving faces. Memory \& Cognition, 32, 640-647.

Lewis, M.B. \& Ellis, H.D. (1999). Repeated Repetition Priming in Face Recognition. Quarterly Journal of Experimental Psychology, 52A, 927-955.

Maylor, E.A. (1998). Retreiving names in old age: Short- and (very) long-term effects of repetition. Memory and Cognition, 26, 309-319.

McClelland, J. L. (1981). Retrieving general and specific information from stored knowledge of specifics. Proceedings of the Third Annual Meeting of the Cognitive Science Society, 170-172.

Morris, C.D., Bransford, J.D., \& Franks, J.J. (1977). Levels of processing versus transfer appropriate processing. Journal of Verbal Learning and Verbal Behavior, 16, 519-533.

Morton, J. (1979). Facilitation in word recognition: Experiments causing change in the logogen model. In P.A. Kolers, M. Wrolstad and H. Bouman (Eds), Processing of Visible Language. New York: Plenum.

Musen, G. (1991). Effects of verbal labelling and exposure duration on implicit memory for visual-patterns. Journal of Experimental Psychology - Learning, Memory and Cognition, 17, 954-962.

Roediger, H.L. \& Challis, B.H. (1992). Effects of exact repetition and conceptual repetition on free recall and primed word fragment completion. Journal of 
Experimental Psychology: Learning, Memory \& Cognition, 18, 3-14.

Roediger, H.L., Weldon, M.S. \& Challis, B.H. (1989). Explaning dissociations between implicit and explicit measures of retention: A processing account. In H.L. Roediger \& F.I.M. Craik (Eds), Varieties of memory and consciousness: Essay in honor of Endel Tulving (p 3-14). Hillsdale, NJ: Erlbaum.

Stevenage, S. \& Lewis, H. (2002). Understanding person acquisition using an interactive activation and competition network. Visual Cognition, 9, 839-867.

Stevenage, S.V. \& Spreadbury, J.H. (2006). Haven't we met before? The effect of facial familiarity on repetition priming. British Journal of Psychology, 97, 79-94.

Warren, C. \& Morton, J. (1982). The effects of priming on picture-recognition. British Journal of Psychology, 73, 117-129 